\title{
Latitudinal variations of TEC over Europe obtained from GPS observations
}

\author{
P. Wielgosz ${ }^{1,3}$, L. W. Baran ${ }^{1}$, I. I. Shagimuratov ${ }^{2}$, and M. V. Aleshnikova ${ }^{2}$ \\ ${ }^{1}$ Insitute of Geodesy, University of Warmia and Mazury, Olsztyn, Poland \\ ${ }^{2}$ ZO IZMIRAN, Kaliningrad, Russia \\ ${ }^{3}$ Department of Civil and Environmental Engineering and Geodetic Science, Ohio State University, USA
}

Received: 18 December 2002 - Revised: 28 May 2003 - Accepted: 4 July 2003 - Published: 1 January 2004

\begin{abstract}
GPS technique has opened broad possibilities to study the TEC distribution on a regular basis. In this paper, the latitudinal dependence of TEC over Europe for geographic latitudes ranging from $40^{\circ} \mathrm{N}$ to $75^{\circ} \mathrm{N}$ is presented. We discuss the day-to-day variations of the latitudinal TEC profiles for a period of 1999 to 2001 for both quiet and disturbed magnetic conditions. More than 4300 TEC profiles were created from the TEC maps with a one-hour interval. GPS data from 65 European permanent stations were used to produce the TEC maps. The comparison of GPS-derived TEC profiles with the IRI model is also discussed.
\end{abstract}

Key words. Ionosphere (mid-latitude ionosphere; ionospheric disturbances)

\section{Introduction}

GPS technique has opened broad possibilities to study the TEC distribution on a regular basis. The analyses of latitudinal TEC dependence obtained from GPS measurements and its comparison with NNSS (Navy Navigation Satellite System) data were earlier merely undertaken in a limited visibility range at a single mid-latitude GPS station by Ciraolo and Spalla (1998). Detailed studies on the latitudinal TEC distribution were carried out only at low latitudes near the equatorial region (Valladares et al., 2001, Basu et al., 2001). The latitudinal behavior of TEC at middle-high latitudes was only examined for single events related to the magnetic storms (Zarraoa and Sardon, 1996; Jakowski et al., 1999; Shagimuratov et al., 2002). In this paper, the data on the latitudinal dependence of TEC over Europe for geographic latitudes ranging from $40^{\circ} \mathrm{N}$ to $75^{\circ} \mathrm{N}$ is presented. In this contribution, we discuss the day to-day variations of the latitudinal TEC profiles for the time period of 1999 to 2001. More than 4300 TEC profiles were created from TEC maps at a onehour interval, which were produced using GPS data from 65 European permanent stations.

Correspondence to: P. Wielgosz (wielgosz.1@osu.edu)
The latitudinal profiles' data may be useful to help upgrade the IRI (International Reference Ionosphere; Bilitza et al., 1993) model. It is also expected that these data will provide a new insight into the structure of the ionospheric trough and its dynamics during magnetospheric disturbances. The latitudinal TEC profiles also demonstrate the evolution of the latitudinal gradients of TEC. Severe horizontal ionospheric gradients may disturb the ambiguity resolution and influence the accuracy of the GPS positioning (Wanninger, 1993).

\section{GPS data and estimation technique}

The GPS data from the European permanent network were used for analysis of latitudinal TEC distribution. A single ground-based receiver can track an individual satellite during 4-6h, providing the ionosphere probing in a broad area. Simultaneous observations of more than 6 satellites in different directions offer a good possibility to map the ionosphere with a high resolution. TEC measurements for an individual satellite pass include both temporal and spatial changes of the ionosphere. Simultaneous multi-station observations were used to resolve both temporal and spatial variations of TEC. Data from 65 European stations were used to reconstruct spatial distribution of TEC from GPS measurements. The distribution of TEC over Europe was analyzed as a time series of TEC maps.

While processing, high precision GPS phase observables were fitted to the pseudo-range measurements, in order to estimate and remove phase ambiguities. However, the phase measurements still contained instrumental biases. These biases (for satellite and receiver) were determined for every individual station using GPS measurements to all satellite passes over a site during a 24-h period, as described in Baran et al. (1997). After the observations from all the EPN stations had been processed, all receiver and satellite specific instrumental biases were removed. As a result, TEC measurements with a 30 -s sampling rate were obtained. 

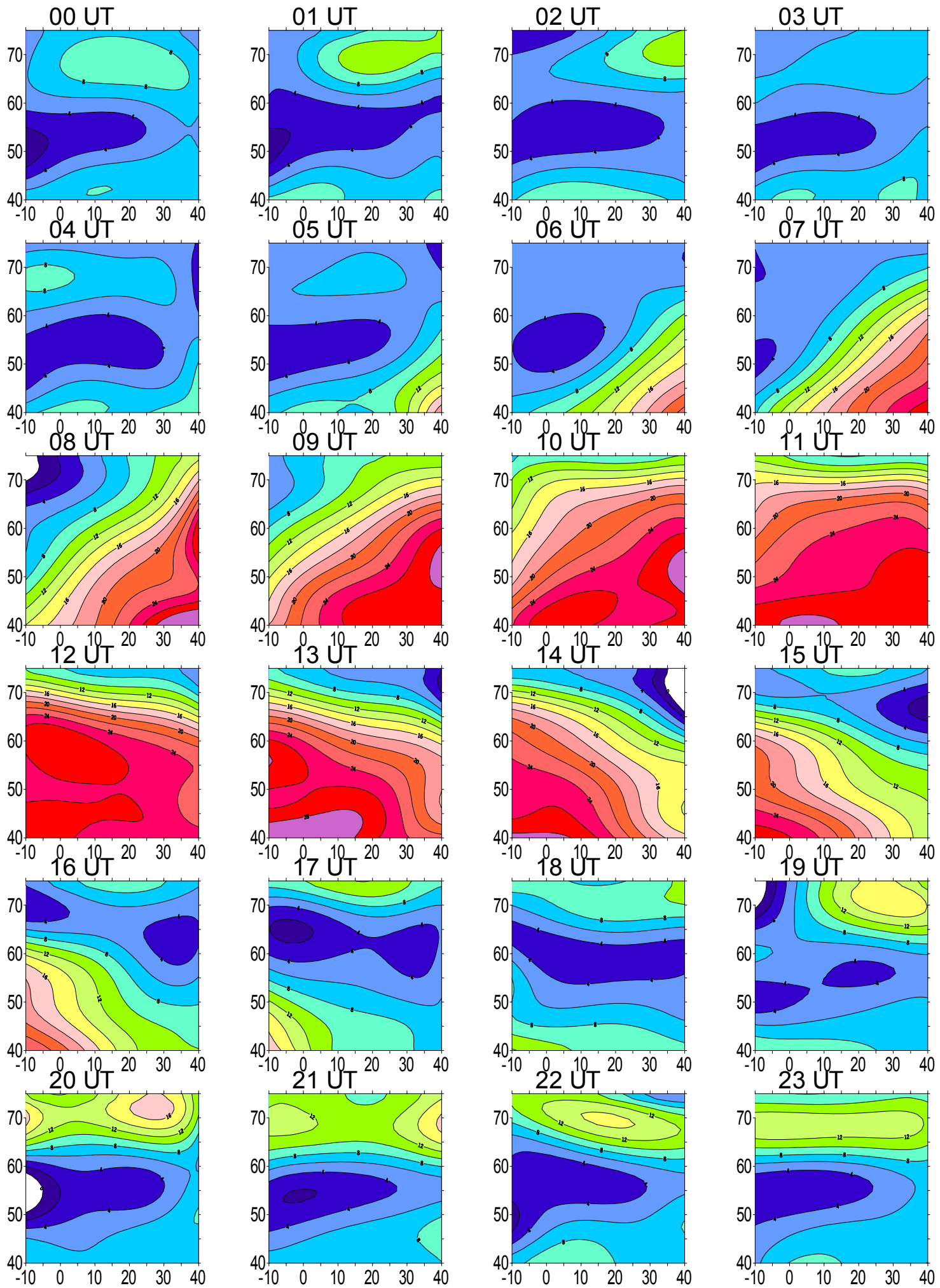

$\begin{array}{lllllllllllllll}0 & 2 & 4 & 6 & 8 & 10 & 12 & 14 & 16 & 18 & 20 & 22 & 24 & 26 & 28\end{array}$

\section{TECU}

Fig. 1. TEC maps for 7 December 1999. The plots demonstrate the development of the trough over Europe. 

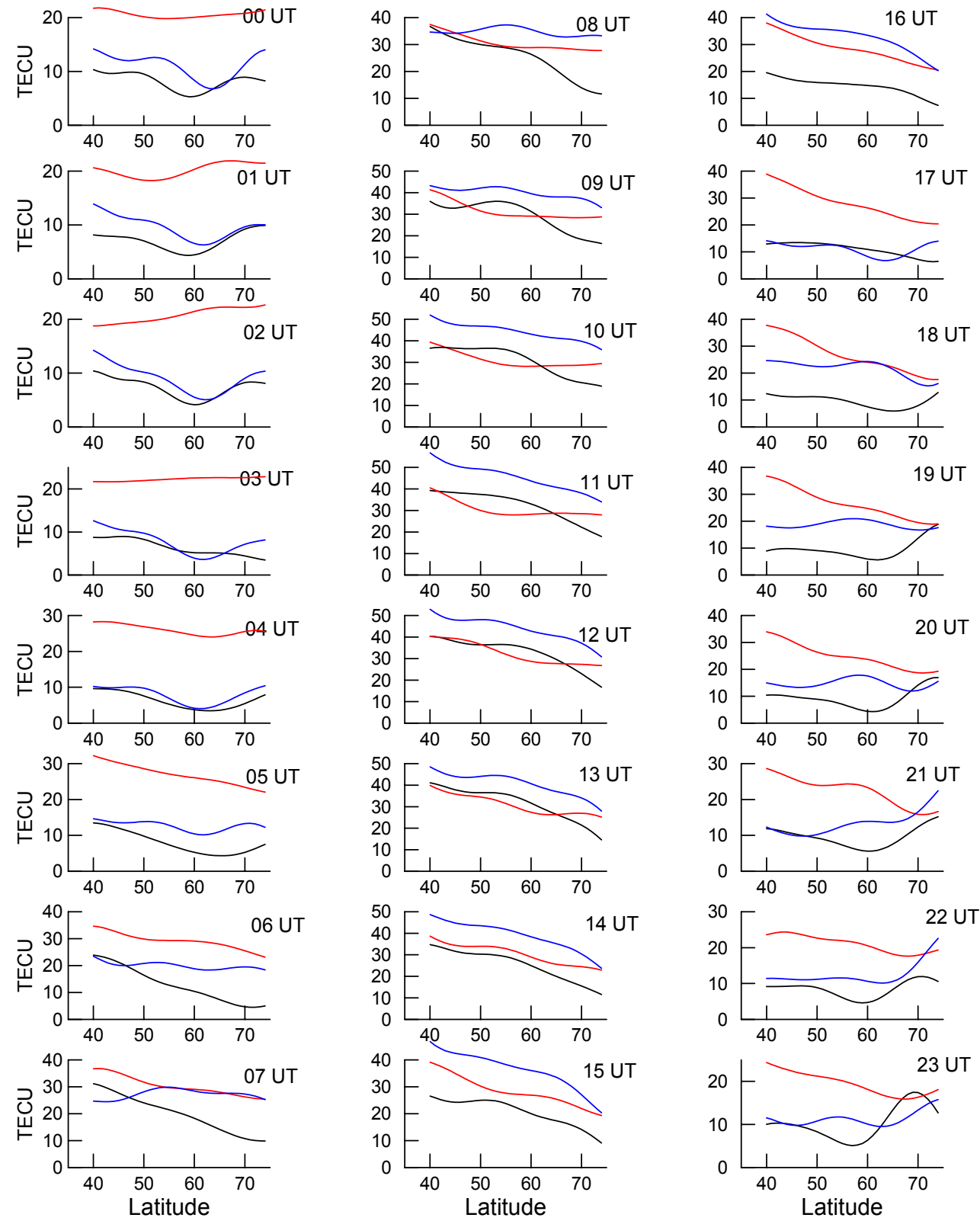

Fig. 2. Latitudinal TEC profiles over Europe at longitude $20^{\circ} \mathrm{E}$. Black line -5 November $1999, \sum K_{p}=9$, red line -18 July 2000 , $\sum K_{p}=12$, blue line -15 March $2001, \sum K_{p}=4$.

A stable solar-fixed reference frame (local time/geographic latitude) was used for estimating TEC. When producing TEC maps, the TEC measurements from all the stations were fitted into spherical harmonic expansion with a maximum degree/order of 16 . The GPS observations with elevation angles above $20^{\circ}$ were used in this fit. The accuracy of TEC maps depends on the spatial gaps in TEC data (Mannucci et al., 1998). A large number of GPS stations used in this study provided a good coverage of the observational data. The coverage is very adequate and yields a reasonable surface harmonic fit and provides TEC maps with a spatial resolution of $150-300 \mathrm{~km}$. The TEC maps were produced with a 15-min interval and 30-s TEC measurements were averaged over this interval.

\section{Results and discussion}

As an example, Fig. 1 illustrates the TEC maps over Europe for 8 December $1999\left(\sum K_{p}=20\right)$. A large-scale structure that can be observed in the maps as longitudinally extended depression of TEC is recognized as the mid-latitude ionospheric trough. In the maps, one may observe the temporal development of the spatial TEC distribution. 

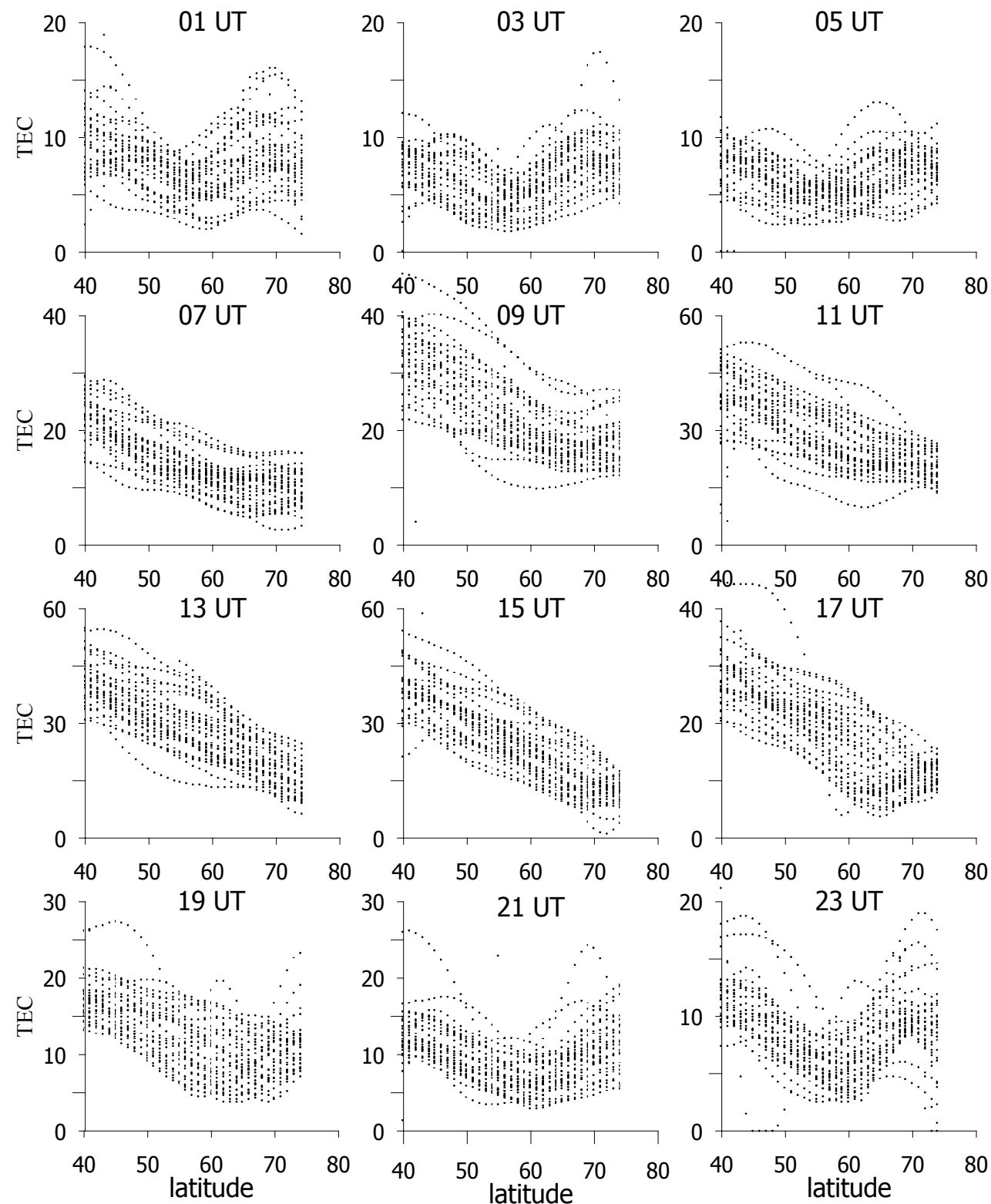

Fig. 3. Scatter plot illustrates day-to-day variations of TEC latitudinal profiles for October 1999.

The latitudinal TEC profiles were constructed from TEC maps at a one-hour interval. Figure 2 presents a comparison of latitudinal TEC plots for different seasons for the quiet days of 5 November 1999, 8 July 2000, and 15 March 2001. The summer and spring daytime TEC slowly decreases towards high latitudes, with latitudinal gradients of about 0.1-0.2 TECU/degree (TECU - TEC Unit). In the evening and at night, during the winter and the equinox, the TEC profiles represent trough-like structure. The sharp increase of TEC that occurred at latitudes of $65-70^{\circ} \mathrm{N}$ demonstrates a distinct polar wall; at the same time the equatorial wall is less pronounced. In winter, the daytime slope of the latitudinal profiles suddenly drops over $\sim 60^{\circ} \mathrm{N}$, causing high latitudinal gradients, which are typical for the ionospheric trough.
A trough-like structure appeared at 14:00 UT ( 15:50 LT). Hereafter, the development of the trough becomes more apparent. The lower boundary of the trough minimum occurred near $70^{\circ} \mathrm{N}$, and then shifted to $60^{\circ} \mathrm{N}$. After midnight, the polar wall became well pronounced, but at the same time the equatorial wall disappeared. The ratio of the minimum TEC value to the polar-wall value amounts to 2 . The lack of the equatorial wall in the latitudinal plot may cause doubt if this latitudinal structure is the real occurrence of the trough. Simultaneously, the polar wall may be interpreted as the nighttime TEC enhancement (Horvath and Essex, 2000). The nighttime TEC increase was also often observed in winter at Kiruna and Troms $\varnothing$ stations at latitude $\sim 70^{\circ} \mathrm{N}$. Intensity of the nighttime TEC enhancement increases during a mag- 

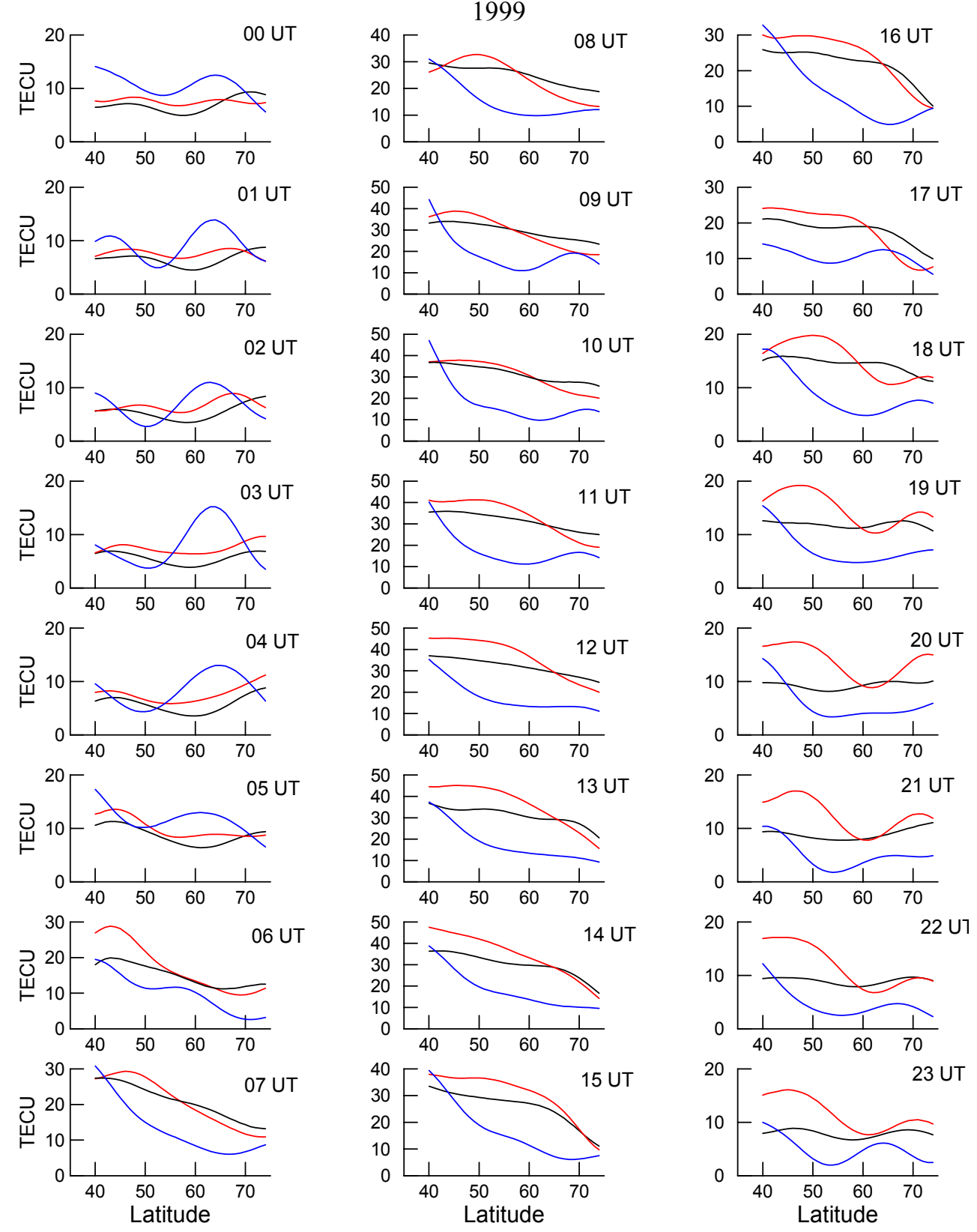

Fig. 4. Latitudinal TEC profiles over Europe at longitude $20^{\circ}$ E. Black line -20 October, $\sum K_{p}=6$, red line -21 October, $\sum K_{p}=25$, blue line -22 October, $\sum K_{p}=46$.

netic disturbance (Zarraoa and Sardon, 1996). During the time period we examined, this feature was observed during quiet magnetic conditions, and appeared regular in winter and frequently in March. In addition, we examined the diurnal variations of TEC over the Kiruna and Troms $\emptyset$ stations during the investigated period, and no explicit nighttime TEC enhancement was detected. The evidence that the observed structure at latitudinal plots is the occurrence of the ionospheric trough is supported by temporal variations of the trough position. In the afternoon, the location of the trough minimum shifted towards the lower latitudes.
The above behavior of latitudinal dependency of TEC is regularly observed in winter conditions. In Fig. 3, the variations of latitudinal TEC profiles are presented on a daily basis for October 1999. A scatter plot also demonstrates the occurrence of the trough in latitudinal TEC profiles. Here, we do not distinguish between disturbed and quiet days. Since the trough location depends on the geomagnetic activity, the occurrence of the trough in a scatter plot is less pronounced.

It should be mentioned that the two troughs can be recognized in the ionosphere - the mid-latitude (main) trough, located on the equatorward side of the auroral oval, and the high-latitude one, located on the poleward side (Werner and 

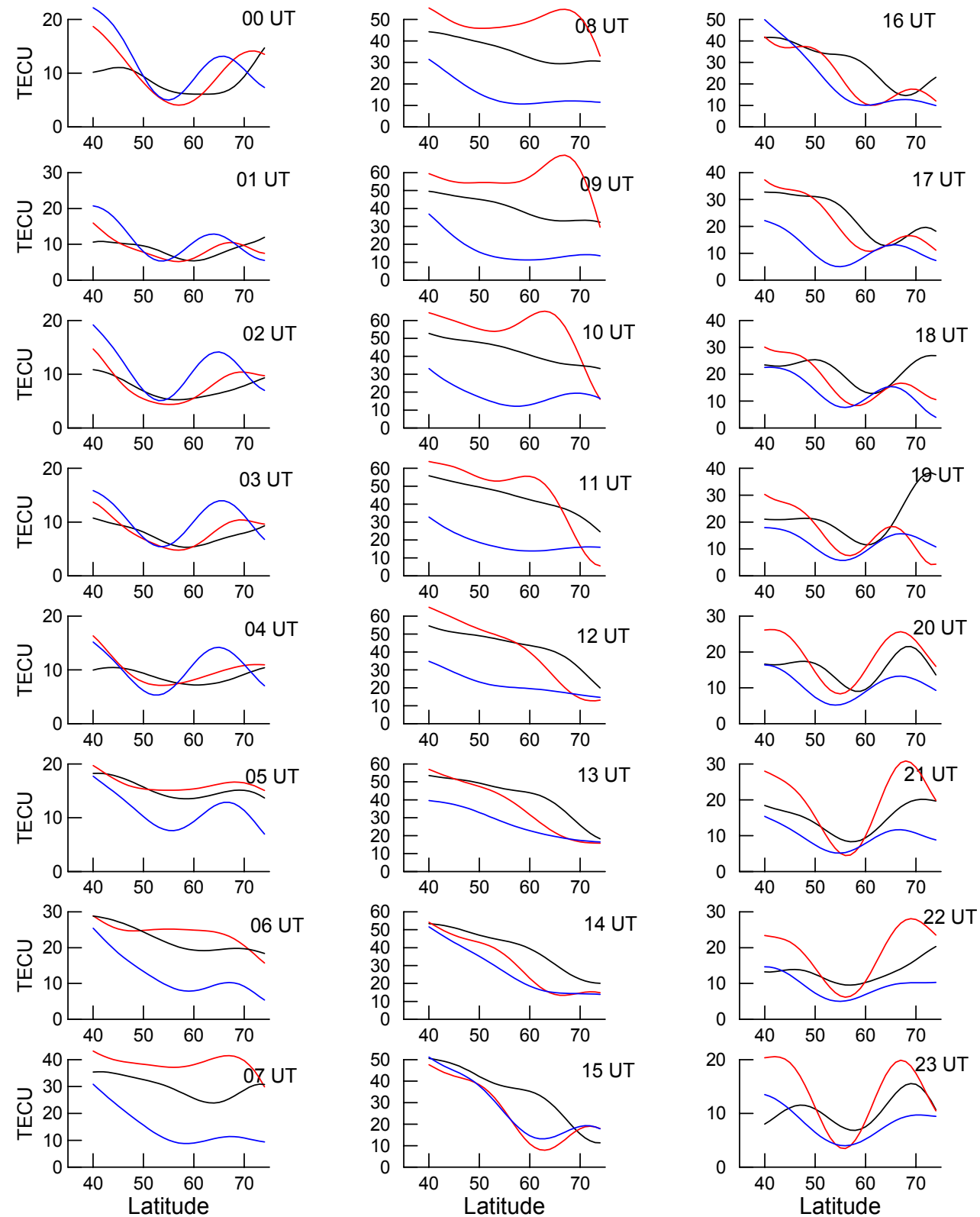

Fig. 5. Latitudinal TEC profiles over Europe at longitude $20^{\circ}$ E. Black line -2 October, $\sum K_{p}=16$, red line -4 October, $\sum K_{p}=40$, blue line -5 October, $\sum K_{p}=53$.

Prolss, 1997). In this study, the highest-latitude station was Ny-Alesund (geographic latitude $78.9^{\circ} \mathrm{N}$ ). This station, depending on the geomagnetic conditions, can probe the mid-, as well as high-latitude trough. Unfortunately, the GPS technique usually does not allow often distinguishing both structures, since at high latitudes GPS satellites are observed at lower elevation angles as compared to mid-latitudes. At the Ny-Alesund station the maximum elevation angle does not exceed $55^{\circ}$. A low elevation GPS signal can intersect both troughs yielding to the smooth picture of the TEC behavior. For high latitude ionospheric studies, the GLONASS constellation with inclination of $65^{\circ}$ seems more convenient.

\subsection{Dynamics of TEC profiles during disturbances}

It is well known that the latitudinal location of the ionospheric trough depends considerably on the geomagnetic activity and it has a great influence on the latitudinal distribution of TEC, as mentioned earlier. In this paper we demonstrate some examples of storm-time variations of latitudinal TEC profiles for different seasons.

Figure 4 shows the dynamics of latitudinal TEC dependency during the storm of 22 October 1999. For comparison, the latitudinal profiles for quiet days are also shown in the same figure. Before the storm, the quiet geomag- 

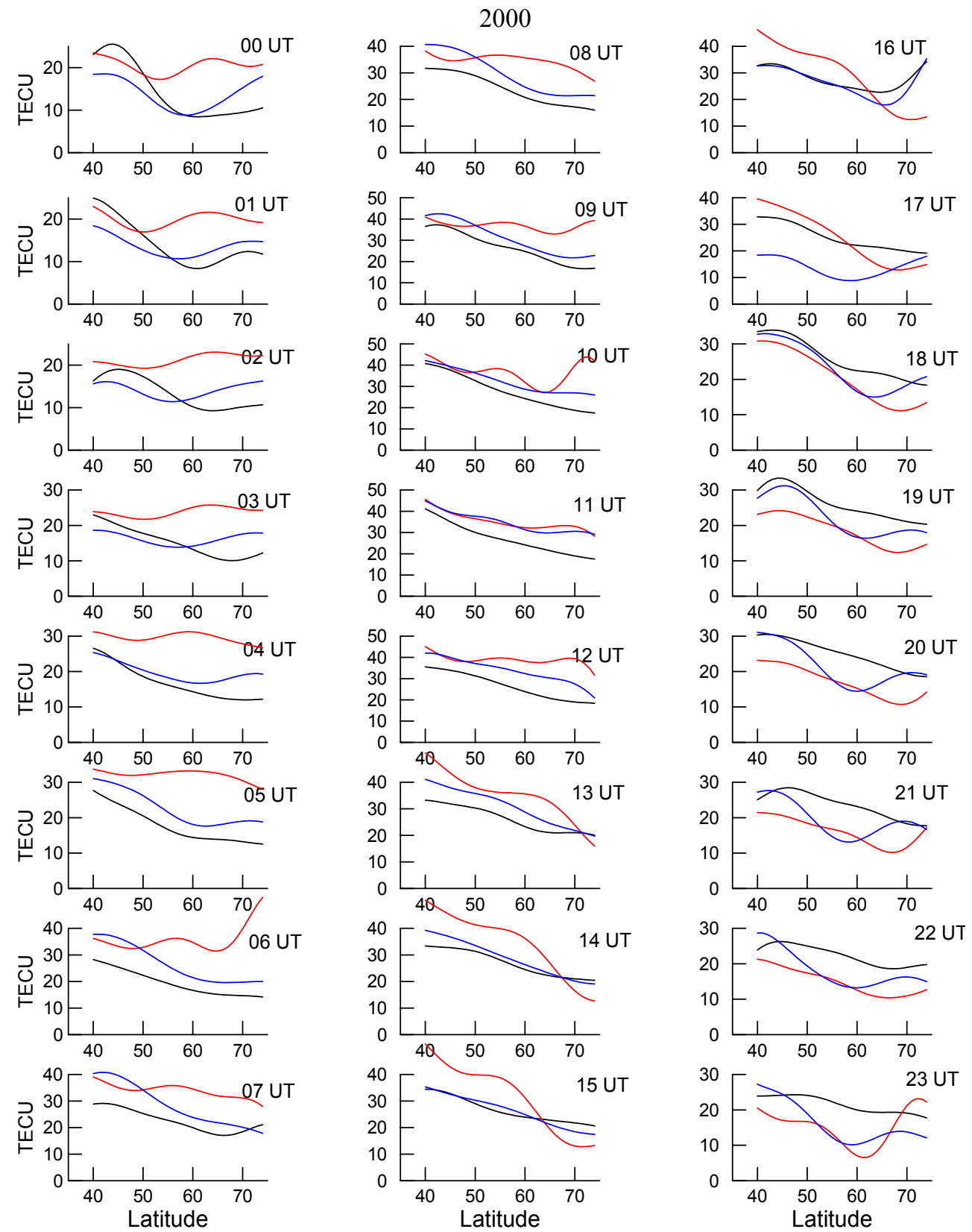

Fig. 6. Latitudinal TEC profiles over Europe at longitude $20^{\circ}$ E. Black line -12 July, $\sum K_{p}=16$, red line -13 July , $\sum K_{p}=30$, blue line -14 July, $\sum K_{p}=36$.

netic condition persisted for three days. On 20 October 1999 the hourly latitudinal profiles display a monotonous character. With the increasing geomagnetic activity, the ionospheric trough appears in the profiles. The trough appeared after 16:00 UT at the latitude of about $70^{\circ} \mathrm{N}$. After midday, the trough migrated towards the lower latitudes, and reached $60^{\circ} \mathrm{N}$ at 23:00 UT. On a severe storm day (22 October 1999) the sum $K_{p}$ amounted to 46 , and $D_{s t}$ dropped to $\sim 220 \mathrm{HT}$. It can be observed in the plot that after 06:00 UT on 22 October, the strong negative effect of the storm began. At latitudes lower than $40^{\circ} \mathrm{N}$ the depression of TEC exceed $150 \%$. In the plot, the dynamics of the trough minimum during 21 October $1999\left(\sum K_{p}=21\right)$ and 22 October $1999\left(\sum K_{p}=46\right)$ is clearly visible. During the storm, the trough minima shifted towards middle latitudes up to $50^{\circ} \mathrm{N}$. The latitudinal profiles exhibited a complex behavior with the presence of the slight polar wall.

In Fig. 5, the effects of the strong storm of October 2000 (maximum $\sum K_{p}=53$ ) are also demonstrated. The storm consisted of a positive (4 October 2000) and negative phases (5 October 2000). On 4 October, a sharp slope appeared in latitudinal TEC dependence after 06:00 UT, which may be interpreted as the equatorial wall of the ionospheric trough. The trough minimum appeared at noon at latitudes near 


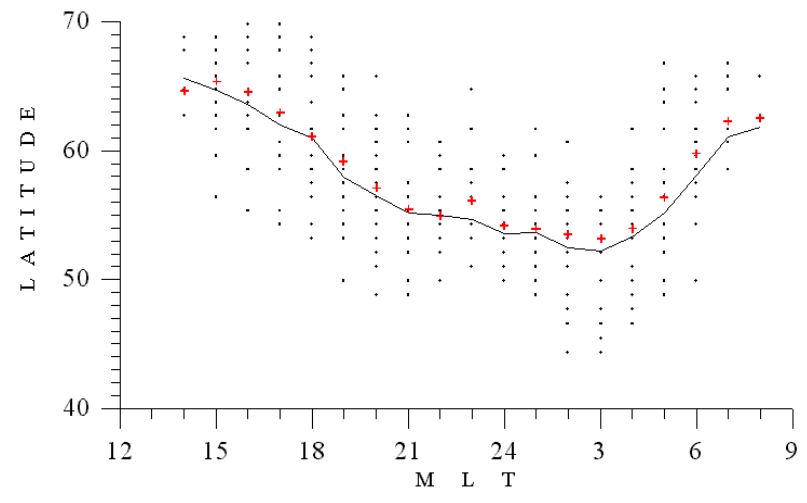

Fig. 7. Position of the trough minimum for October 1999 (in CGL and MLT). Dots - daily values, crosses - monthly averages, black line - approximation.

$70^{\circ} \mathrm{N}$. In contrast, during the storm of October 1999, the ionospheric trough demonstrated clearly sharp equatorial and polar walls.

Figure 6 illustrates the variations of the latitudinal TEC profiles for the summer storm of 13-14 July 2000. During the quiet day of 12 July 2000, the latitudinal profiles demonstrate a steady slope, with a decrease of TEC towards higher latitudes. During the storm, the latitudinal dependency also shows a complex behavior. We notice the occurrence of the trough-like structures in latitudinal TEC profiles during the winter, as well as during the summer.

\subsection{Data analysis and the trough minimum modeling}

The above analyses of the latitudinal profiles of TEC showed that the latitudinal distribution essentially depends on the occurrence of the ionospheric trough. According to data availability, the latitudinal profiles were derived from TEC maps by plotting the hourly TEC values against geographic latitudes. The plots were used to identify the trough and determine the position of the trough minimum during the high solar activity period of October to December 1999. In order to analyze temporal variations of the location of the trough minimum, the corrected geomagnetic latitude (CGL) and the magnetic local time (MLT) coordinate system was used. These coordinates were selected as most suitable to represent the data. We did not distinguish between the quiet and disturbed conditions. Figure 7 shows the location of all trough minima for October 1999. In spite of the considerable scatter, the local time variations of the trough minimum location are clearly visible. A thin line shows the average location of the trough minimum. The scatter of the trough location exhibits day-to-day variations of the trough minimum, which are generally related to the variations of magnetic activity. At noon, the trough was located at higher latitudes, and in the afternoon, its position shifted towards lower latitudes. In the early morning hours, the trough reached a position closest to the equator. The local time variations of the trough are similar to the measurements from the other satellite techniques, e.g. Werner and Prolss (1997). Figure 7 shows that the curve of the average trough position is not symmetric with respect to midnight. The TEC data were used to model the local time variation of the trough minimum. An approximation analogous to the one applied by Werner and Prolss (1997) was used (a Fourier series expansion of degree 2, which was fitted to the average curve using a least-squares adjustment):

$$
\begin{gathered}
\Phi(\mathrm{MLT})=a_{0}+a_{1} \cos \left(\frac{2 \pi}{24} \mathrm{MLT}\right)+b_{1} \sin \left(\frac{2 \pi}{24} \mathrm{MLT}\right) \\
+a_{2} \cos \left(\frac{4 \pi}{24} \mathrm{MLT}\right)+b_{2} \sin \left(\frac{4 \pi}{24} \mathrm{MLT}\right),
\end{gathered}
$$

where: $\Phi$ corrected geomagnetic latitude, MLT is the magnetic local time (hours), $a_{0}=37.49, a_{1}=0.28, b_{1}=-2.58$, $b_{2}=0.30$.

\subsection{Comparison of GPS-derived TEC and the IRI model}

Figures 8 and 9 present a comparison of the latitudinal profiles of GPS and IRI TEC for 15 December 1999 $\left(\sum K_{p}=6.6\right)$ and 4 April $2001\left(\sum K_{p}=26.0\right)$. For comparison purposes, the individual days with a typical pattern of occurrence for the latitudinal variations of TEC were selected. In this paper, only the behavior of the TEC profiles is discussed.

The IRI profiles show a repetitive character with the weak variations of TEC with latitude. During December, as well as during April, IRI TEC increases slightly with latitude showing the positive latitudinal gradients. In contrast, GPS TEC decreases toward higher latitude, demonstrating the essentially negative latitudinal gradients. GPS-derived TEC demonstrates a depression around $60^{\circ} \mathrm{N}$, which is recognized as the ionospheric trough. The latitudinal profiles of GPS TEC show a great variability in latitudinal dependency. Generally, there is an essential discrepancy between the latitudinal dependency of IRI and the GPS-derived TEC. IRI TEC data do not represent the ionospheric trough and as a consequence, the latitudinal gradients of GPS TEC are 2-3 times greater. In addition, the latitudinal gradients in GPS-derived TEC and IRI TEC have the opposite signs. The maximum discrepancy took place near the trough minima at the latitudes of $55-65^{\circ} \mathrm{N}$, and, depending on geomagnetic conditions, it reached 20-30 TECU. The absolute TEC level at the lower latitudes $\left(\sim 40^{\circ} \mathrm{N}\right)$ is quite similar, but differences between GPS and IRI TEC reached a factor of 2-3 for the latitudes over $60^{\circ} \mathrm{N}$ (Fig. 9). A good possibility to validate GPS TEC observations is a comparison to TOPEX/POSEIDON TEC data (Codrescu et al., 2000). We consider including TOPEX/POSEIDON TEC data in future studies. A comparison of both techniques over the North and Baltic Seas, as well as over the North-East Atlantic Ocean might be interesting and is also considered for future research. 

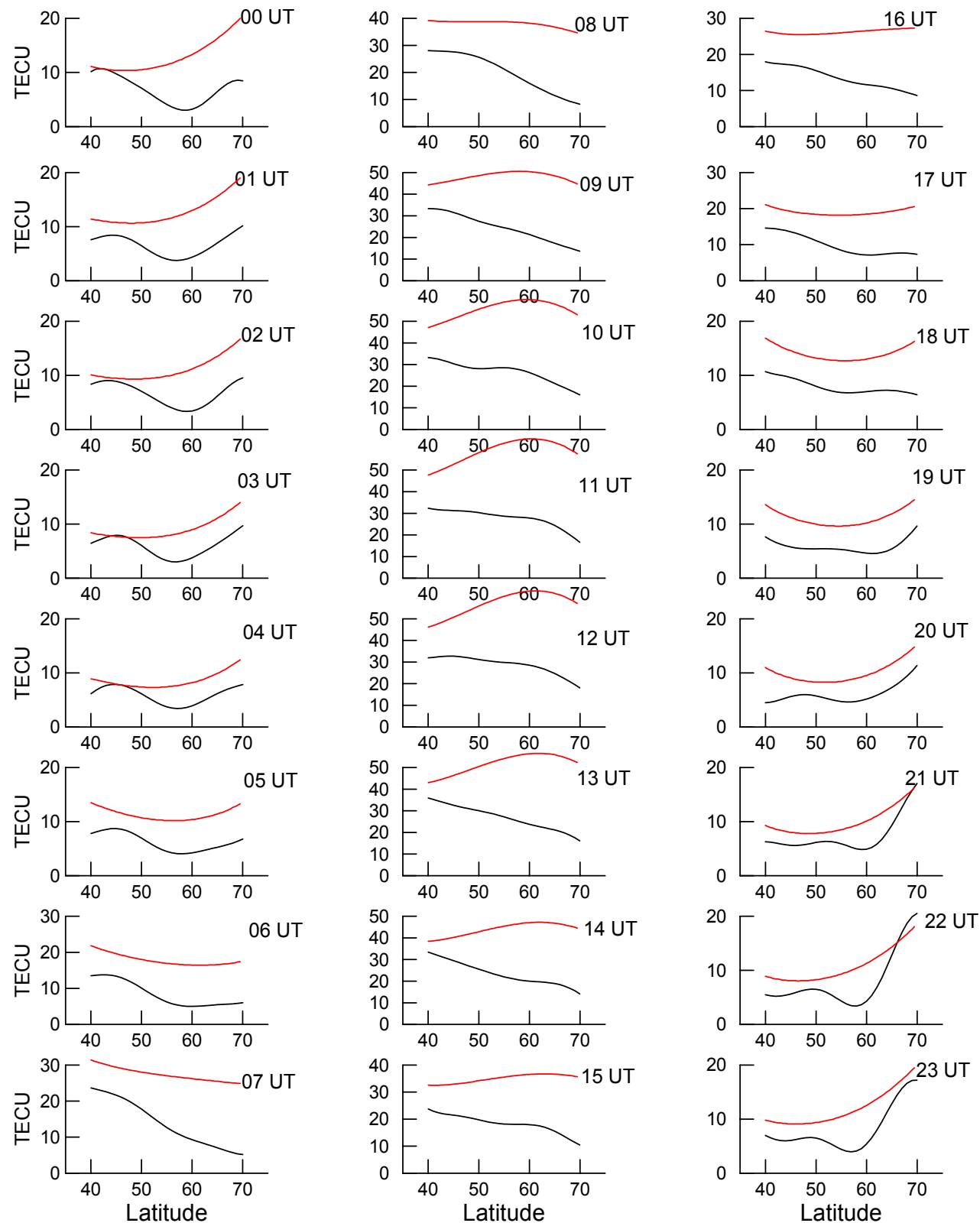

Fig. 8. Comparison between latitudinal profiles of GPS-derived TEC (black) and IRI model (red) for December 1999.

\section{Summary}

GPS observations can provide information about the TEC distribution on a regular basis. In the preliminary investigations, the analyses of the TEC latitudinal profiles over Europe were carried out during the solar maximum activity for both quiet and disturbed conditions.

Diurnal and seasonal variations were obtained from the TEC maps. Day-to-day variations were found to be maximum in winter and minimum in summer. During the daytime, TEC decreases onotonously towards the high latitudes. The latitudinal gradients are larger in winter than in summer. The scatter of latitudinal profiles reaches its maximum dur- ing the night hours. This phenomenon can be related to the occurrence of the ionospheric trough. For the winter conditions, the occurrence of the trough takes place in the afternoon. In August trough-like structures in the latitudinal profiles are often observed at night. During the disturbances, the latitudinal dependence is more variable. We relate this effect to the migration of the position of the trough minimum, which depends on the geomagnetic activity. The comparison of GPS-derived TEC profiles with the IRI model demonstrates that the IRI model might not reproduce the latitudinal TEC variations correctly. 

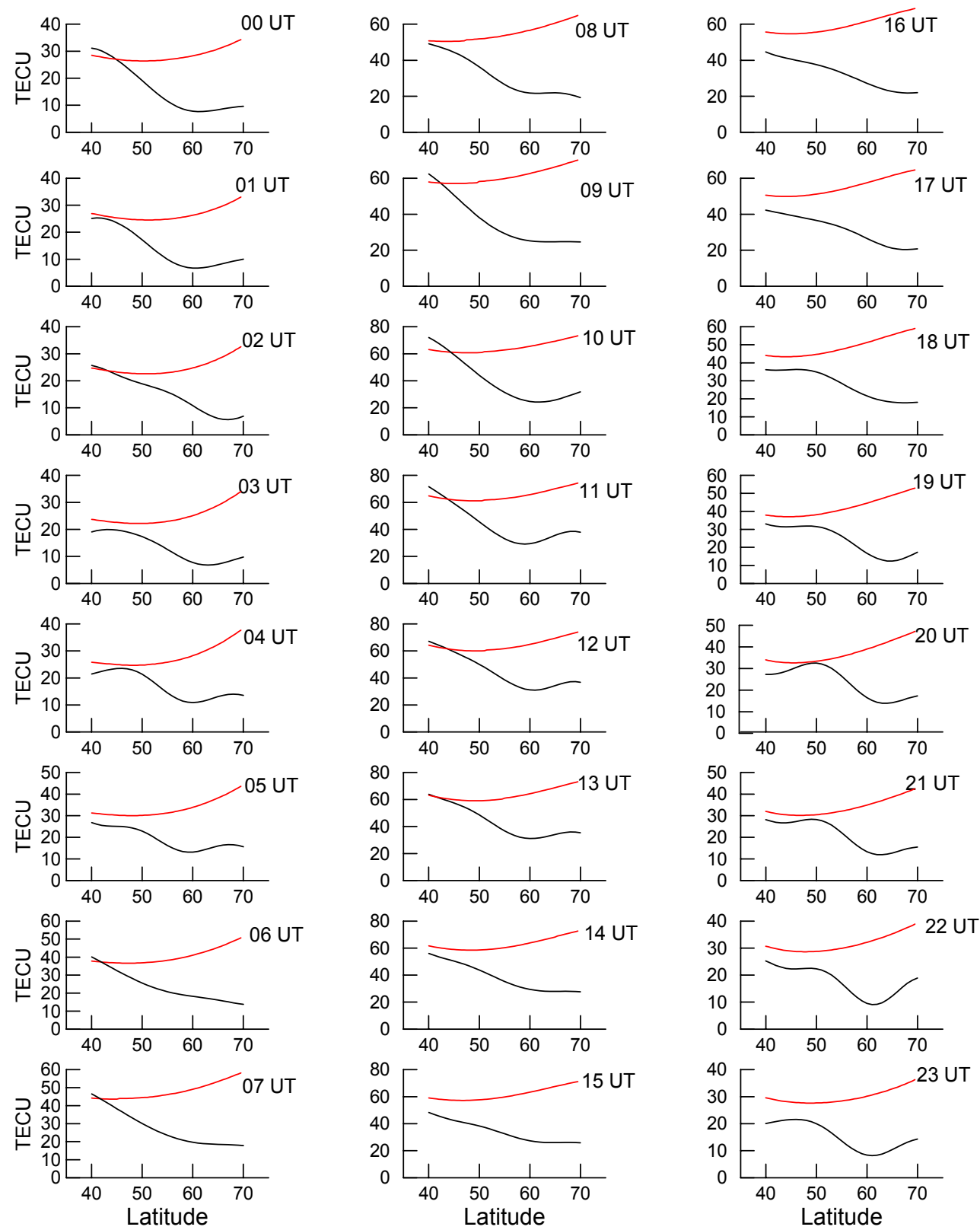

Fig. 9. Comparison between latitudinal profiles of GPS-derived TEC (black) and IRI model (red) for April 2001.

Acknowledgements. Pawel Wielgosz has been supported by the Foundation for Polish Science. This work has been supported by the Polish Committee for Scientific Research: grant No 5 T12E 033 23.

Topical Editor M. Lester thanks two referees for their help in evaluating this paper. The author is grateful to the reviewers for their thoughtful comments.

\section{References}

Baran, L. W., Shagimuratov, I. I., and Tepenitsina, N. J.: The Use of GPS for Ionospheric Studies, Artificial Satellites, Vol. 32, No 1, 49-60, 1997.
Basu, S., Valladares, C. E., Yeh, H. C., and Su, S. Y.: Ionospheric effects of major magnetic storms during the International Space Weather Period of September and October 1999: GPS observation, VHF/UHF scintillations, an in situ density structures at middle and equatorial latitudes, J. Geophys. Res., 106, 30389 $30413,2001$.

Bilitza, D., Rawer, K., Bossy, L., and Gulayeva, T.: International Reference Ionosphere - Past, Present, Future, Adv. Space Res., 13, 3, 3-23, 1993.

Ciraolo, L. and Spalla, P.: Preliminary study of the latitudinal dependence of TEC, Adv. Space. Res., 22, 6, 807-810, 1998.

Codrescu, M. V., Beierle, K. L., Fuller-Rowell, T. J., Palo, S. E., and Zhang, X.: More total electron content climatology from TOPEX/Poseidon measurements, Radio Science, 36, 3, 325, 
2000.

Horvath, I. and Essex, E. A.: Using observations from the GPS and TOPEX satellites to investigate night-time TEC enhancement at mid-latitudes in the southern hemisphere during a low sunspot number period, J. Atmos. Terr. Phys., 62, 371-391, 2000.

Jakowski, N., Schlutter, S., and Sardon, E.: Total electron content of the ionosphere during geomagnetic storm on 10 January 1997, J. Atmos. Terr. Phys., 61, 299-307, 1999.

Mannucci, A. J., Wilson, B. D., Yuan, D. N., Ho, C. H., Lindqwister, U. J., and Runge, T. F.: A global mapping technique for GPSderived ionospheric TEC measurements, Radio Science, 33, 3, $565-582,1998$

Shagimuratov, I. I., Baran, L. W., Wielgosz, P., and Yakimova, G. A.: The structure of mid- and high-latitude ionosphere during September 1999 storm event obtained from GPS observations,
Ann. Geophys., 20, 1-6, 2002.

Valladares, C. E., Basu, S., Croves, K., Hagan, M. P., Hyssel, D., Mazzella, Jr., A. J., and Sheehan, R. E.: Measurements of the latitudinal distribution of total electron content during equatorial spread F-events, J. Geophys. Res., 106, 29 133-29 152, 2001.

Wanninger, L.: The occurrance of ionospheric disturbances above Japan and their effects on GPS positioning, Paper presented at the 8th International Symposium on Recent Crust Movemens (CRCM 93), Kobe, Japan, December 1993.

Werner S. and Prolss, G. W.: The position of the ionospheric trough as a function of local time and magnetic activity, Adv. Space Res., vol. 20, No. 9, 1717-1722, 1997.

Zarraoa, N. and Sardon, E.: Test of GPS for permanent ionospheric TEC monitoring at high latitudes, Ann. Geophys., 14, 11-19, 1996. 